Research Article

\title{
Nonlinear Dynamic Characteristics of Fixed-Axis Gear Wear in Multistage Gear Transmission Systems
}

\author{
Xin Wang (iD \\ School of Mechanical Engineering, Baoji University of Arts and Sciences, Baoji 721016, China \\ Correspondence should be addressed to Xin Wang; 46607190@qq.com
}

Received 21 December 2018; Accepted 10 April 2019; Published 20 June 2019

Academic Editor: Zhixiong Li

Copyright (๑) 2019 Xin Wang. This is an open access article distributed under the Creative Commons Attribution License, which permits unrestricted use, distribution, and reproduction in any medium, provided the original work is properly cited.

\begin{abstract}
With the increasing service life of a gear transmission system, the gear teeth become constantly worn and the gear clearance increases. The increase in the clearance will produce a series of nonlinear changes that change the stability of the system and can even cause the loss of stability. In this paper, dimensionless dynamic equations of a multistage gear transmission system that contains a two-stage fixed-axis gear and a one-stage planetary gear were derived. The wear fault was simulated by changes in the gear clearance. System bifurcation diagrams with an increase in the clearance were studied. The motion state and transition process of the multistage gear transmission system with a wear fault were studied using the Poincare section. The change in the spectrum characteristics with an increase in the clearance was analyzed. The frequency spectrum characteristics of the wear fault were discovered. The vibration mechanism and a fault wear diagnosis method in a multistage gear transmission system were obtained.
\end{abstract}

\section{Introduction}

With the increase in the service life of a gear transmission system, the gear teeth are continuously worn, resulting in an increase in the gear clearance. Clearance is the main reason for collision motion inside this system. Clearance will make the motion state of the system change or even create instability. Therefore, it is very important to study the wear mechanism and the change in the system nonlinear state, as these attributes are of great significance for the design, monitoring, and diagnosis of the system.

Currently, many scholars have researched the mechanism of wear failure, including the friction and wear mechanism of the medium belt [1], theoretical and experimental investigations into the teeth wear of spur gears of heavy-duty machinery [2], measurement of the mean wear coefficient [3], theoretical study of wear in internal gears [4], prediction of the steady-state wear rate [5], and the wear characteristics, surface finish, and microgeometry [6].

In the field of dynamics, Wojnarowski and Onishchenko [7] carried out analytical and experimental investigations of the influence of the deformation and wear on spur gear dynamics. Liu et al. [8] examined the dynamic response of the spur gear pair system and the interactions between bearing clearance and the backlash. Ding and Kahraman [9] studied the interaction between gear surface wear and gear dynamic response. Osman and Velex [10] studied the static and dynamic simulations of mild abrasive wear. However, this literature did not consider the nonlinear characteristics of the system. Shen et al. [11] focused on the nonlinear dynamics of a spur gear pair with a slight wear fault, where the backlash, time-varying stiffness, and wear fault were all included. These studies all focused on the single pair gear model and neglected the coupling characteristics between multistage gears. Therefore, it is necessary to further investigate the nonlinear dynamic characteristics of a multistage gear transmission system wear fault.

For wear fault diagnosis, most of the studies mainly use the signal processing method to extract fault signals, such as the gear wear monitoring by a modulation signal bispectrum based on motor current signal analysis [12], helical gear wear monitoring [13], and fault diagnosis of gear wearing based on order spectrum analysis [14]. Plint and Alliston-Greiner 
[15] proposed a new wear criterion: the energy pulse. He [16] proposed a novel nonlinear time-frequency feature based on a time-frequency manifold (TFM) technique. Liu et al. [17] proposed a dynamic wear prediction methodology to investigate the coupling effects between surface wear and the dynamics of spur gear systems. This paper will also use the nonlinear wear fault time-frequency characteristics to present a diagnostic method for wear faults.

In this paper, a nonlinear dynamic model of a multistage gear transmission system consisting of a two-stage fixed-axis gear and a one-stage planetary gear was established. The simulation method was used to analyze the bifurcation characteristics of the system under different clearances to determine the wear excitation frequency range and the changes in the system motion state to understand the frequency characteristics of the system. The transition process and fault frequency characteristics of each motion state under different excitation frequencies are discussed. The vibration mechanism and a diagnostic method of wear fault were obtained.

\subsection{Torsion Dynamics Model of a Multistage Gear Trans-} mission System. The system studied in this paper is a test rig with a multistage gear transmission system that contains a two-stage, fixed-axis gear and a one-stage planetary gear, where spur gears 1 and 2 compose the $1^{\text {st }}$ stage fixed-axis gear for the input, spur gears 3 and 4 compose the $2^{\text {nd }}$ stage fixed-axis gear, and the planet carrier is for the output. The torsional dynamic model is established using the lumped mass method (Figure 1). The model does not consider the transverse vibration displacement of the gears. The gear parameters are simulated with a spring and a damper.

In Figure $1, \theta_{\mathrm{s}}, \theta_{\mathfrak{c}}, \theta_{\mathrm{pn}}, \theta_{1}, \theta_{2}, \theta_{3}$, and $\theta_{4}$ represent the angular displacements of the sun gear, planet carrier, planetary gear $n(n=1,2,3,4)$, and spur gears $1,2,3$, and 4 , respectively. Throughout this paper, the subscripts s, c, pn, r, and 1,2,3, and 4 denote the sun gear, planet carrier, planetary gear, ring gear, and spur gears $1,2,3$, and 4 , respectively. The quantities $r_{\mathrm{s}}, r_{\mathrm{c}}, r_{\mathrm{pn}}, r_{1}, r_{2}, r_{3}$, and $r_{4}$ are the base circle radius values of the gears. The quantities $K_{\text {spn }}(t), K_{\mathrm{rpn}}(t), K_{1}(t)$, and $K_{2}(t)$ denote the meshing stiffness of the sun gear with planetary gear $n$, the ring gear with planetary gear $n$, the $1^{\text {st }}$ stage fixed gear, and the $2^{\text {nd }}$ stage fixed gear, respectively. The quantities $C_{\mathrm{spn}}, C_{\mathrm{rpn}}, C_{1}$, and $C_{2}$ denote the damping of the sun gear with planetary gear $n$, the ring gear with planetary gear $n$, the $1^{\text {st }}$ stage fixed gear, and the $2^{\text {nd }}$ stage fixed gear, respectively. $T_{\text {in }}$ is the input, and $T_{\text {out }}$ is the output.

1.1.1. Motion Differential Equations of the System. By using the Lagrangian equation, the clearance, time-varying meshing stiffness, and composite error are considered to establish the motion differential equations of the system. After that, the motion differential equation is processed in a dimensionless way. This process has been deduced and described in detail in paper [18]. Only the final system dimensionless motion differential equations are listed here:

$$
\begin{aligned}
& \ddot{\bar{x}}_{1}+\frac{C_{1}}{m_{\mathrm{e} 1} w_{\mathrm{h}}} \dot{\bar{x}}_{1}+\frac{K_{1}(\tau)}{m_{\mathrm{e} 1} w_{\mathrm{h}}^{2}} f\left(\bar{x}_{1}\right)-\frac{C_{2}}{m_{\mathrm{e} 2} w_{\mathrm{h}}} \dot{\bar{x}}_{2}-\frac{K_{2}(\tau)}{m_{\mathrm{e} 2} w_{\mathrm{h}}^{2}} f\left(\bar{x}_{2}\right) \\
& =\frac{T_{\mathrm{in}} r_{1}}{J_{1} w_{\mathrm{h}}^{2} b_{1}}+\frac{e_{\mathrm{a} 1}}{b_{1}} \Omega_{1}^{2} \sin \left(\Omega_{1} \tau+\phi_{1}\right) \\
& \ddot{\bar{x}}_{2}-\frac{C_{1}}{m_{\mathrm{e} 1} w_{\mathrm{h}}} \dot{\bar{x}}_{1}-\frac{K_{1}(\tau)}{m_{\mathrm{e} 2} w_{\mathrm{h}}^{2}} f\left(\bar{x}_{1}\right)+\frac{C_{2}}{m_{\mathrm{e} 3} w_{\mathrm{h}}} \dot{\bar{x}}_{2}+\frac{K_{2}(\tau)}{m_{\mathrm{e} 3} w_{\mathrm{h}}^{2}} f\left(\bar{x}_{2}\right) \\
& -\sum_{n=1}^{4} \frac{C_{\mathrm{spn}}}{m_{4 \mathrm{~s}} w_{\mathrm{h}}} \dot{\bar{x}}_{\mathrm{spn}}-\sum_{n=1}^{4} \frac{K_{\mathrm{spn}}(\tau)}{m_{4 \mathrm{~s}} w_{\mathrm{h}}^{2}} f\left(\bar{x}_{\mathrm{spn}}\right) \\
& =\frac{e_{\mathrm{a} 2}}{b_{1}} \Omega_{2}^{2} \sin \left(\Omega_{2} \tau+\phi_{2}\right), \\
& \ddot{\bar{x}}_{\mathrm{spn}}+\frac{1}{m_{4 \mathrm{~s}} w_{\mathrm{h}}} \sum_{n=1}^{4} C_{\mathrm{spn}} \dot{\bar{x}}_{\mathrm{spn}}+\frac{1}{m_{\mathrm{c}} w_{\mathrm{h}}} \sum_{n=1}^{4} C_{\mathrm{spn}} \dot{\bar{x}}_{\mathrm{spn}} \\
& +\frac{1}{m_{\mathrm{pn}} w_{\mathrm{h}}} C_{\mathrm{spn}} \dot{\bar{x}}_{\mathrm{spn}}+\frac{1}{m_{4 \mathrm{~s}} w_{\mathrm{h}}^{2}} \sum_{n=1}^{4} K_{\mathrm{spn}}(\tau) f\left(\bar{x}_{\mathrm{spn}}\right) \\
& +\frac{1}{m_{\mathrm{c}} w_{\mathrm{h}}^{2}} \sum_{n=1}^{4} K_{\mathrm{spn}}(\tau) f\left(\bar{x}_{\mathrm{spn}}\right)+\frac{1}{m_{\mathrm{pn}} w_{\mathrm{h}}^{2}} K_{\mathrm{spn}}(\tau) f\left(\bar{x}_{\mathrm{spn}}\right) \\
& -\frac{1}{m_{\mathrm{pn}} w_{\mathrm{h}}} C_{\mathrm{rpn}} \dot{\bar{x}}_{\mathrm{rpn}}+\frac{1}{m_{\mathrm{c}} w_{\mathrm{h}}} \sum_{n=1}^{4} C_{\mathrm{rpn}} \dot{\bar{x}}_{\mathrm{rpn}}-\frac{1}{m_{\mathrm{pn}} w_{\mathrm{h}}^{2}} K_{\mathrm{rpn}}(\tau) f\left(\bar{x}_{\mathrm{rpn}}\right) \\
& +\frac{1}{m_{\mathrm{c}} w_{\mathrm{h}}^{2}} \sum_{n=1}^{4} K_{\mathrm{rpn}}(\tau) f\left(\bar{x}_{\mathrm{rpn}}\right)-\frac{r_{4} C_{2}}{m_{4 \mathrm{~s}} r_{\mathrm{s}} w_{\mathrm{h}}} \dot{\bar{x}}_{2} \\
& -\frac{r_{4} K_{2}(\tau)}{m_{4 \mathrm{~s}} r_{\mathrm{s}} w_{\mathrm{h}}^{2}} f\left(\bar{x}_{2}\right)=\frac{r_{\mathrm{c}} T_{\mathrm{out}}}{J_{\mathrm{ce}} w_{\mathrm{h}}^{2} b_{1}}+\frac{e_{\mathrm{aspn}}}{b_{1}} \Omega_{\mathrm{spn}}^{2} \sin \left(\Omega_{\mathrm{spn}} \tau+\phi_{\mathrm{spn}}\right), \\
& \ddot{\bar{x}}_{\mathrm{rpn}}-\frac{1}{m_{\mathrm{pn}} w_{\mathrm{h}}} C_{\mathrm{spn}} \dot{\bar{x}}_{\mathrm{spn}}+\frac{1}{m_{\mathrm{c}} w_{\mathrm{h}}} \sum_{n=1}^{4} C_{\mathrm{spn}} \dot{\bar{x}}_{\mathrm{spn}} \\
& -\frac{1}{m_{\mathrm{pn}} w_{\mathrm{h}}^{2}} K_{\mathrm{spn}}(\tau)\left(\bar{x}_{\mathrm{spn}}\right)+\frac{1}{m_{\mathrm{c}} w_{\mathrm{h}}^{2}} \sum_{n=1}^{4} K_{\mathrm{spn}}(\tau) f\left(\bar{x}_{\mathrm{spn}}\right) \\
& +\frac{1}{m_{\mathrm{pn}} w_{\mathrm{h}}} C_{\mathrm{rpn}} \dot{\bar{x}}_{\mathrm{rpn}}-\frac{1}{m_{\mathrm{c}} w_{\mathrm{h}}} \sum_{n=1}^{4} C_{\mathrm{rpn}} \dot{\bar{x}}_{\mathrm{rpn}} \\
& +\frac{1}{m_{\mathrm{pn}} w_{\mathrm{h}}^{2}} K_{\mathrm{rpn}}(\tau) f\left(\bar{x}_{\mathrm{rpn}}\right)-\frac{1}{m_{\mathrm{c}} w_{\mathrm{h}}^{2}} \sum_{n=1}^{4} K_{\mathrm{rpn}}(\tau) f\left(\bar{x}_{\mathrm{rpn}}\right) \\
& =\frac{r_{\mathrm{c}} T_{\mathrm{out}}}{J_{\mathrm{ce}} w_{\mathrm{h}}^{2} b_{1}}-\frac{e_{\mathrm{arpn}}}{b_{1}} \Omega_{\mathrm{rpn}}^{2} \sin \left(\Omega_{\mathrm{rpn}} \tau+\phi_{\mathrm{rpn}}\right) .
\end{aligned}
$$

1.1.2. Wear Fault. The gear tooth surface will wear out with an increase in the running time. The clearance between the teeth will change when wear occurs. When gear teeth are evenly worn, the tooth clearance will be larger than normal. To model wear failure, Flodin and Andersson [19] simulated 


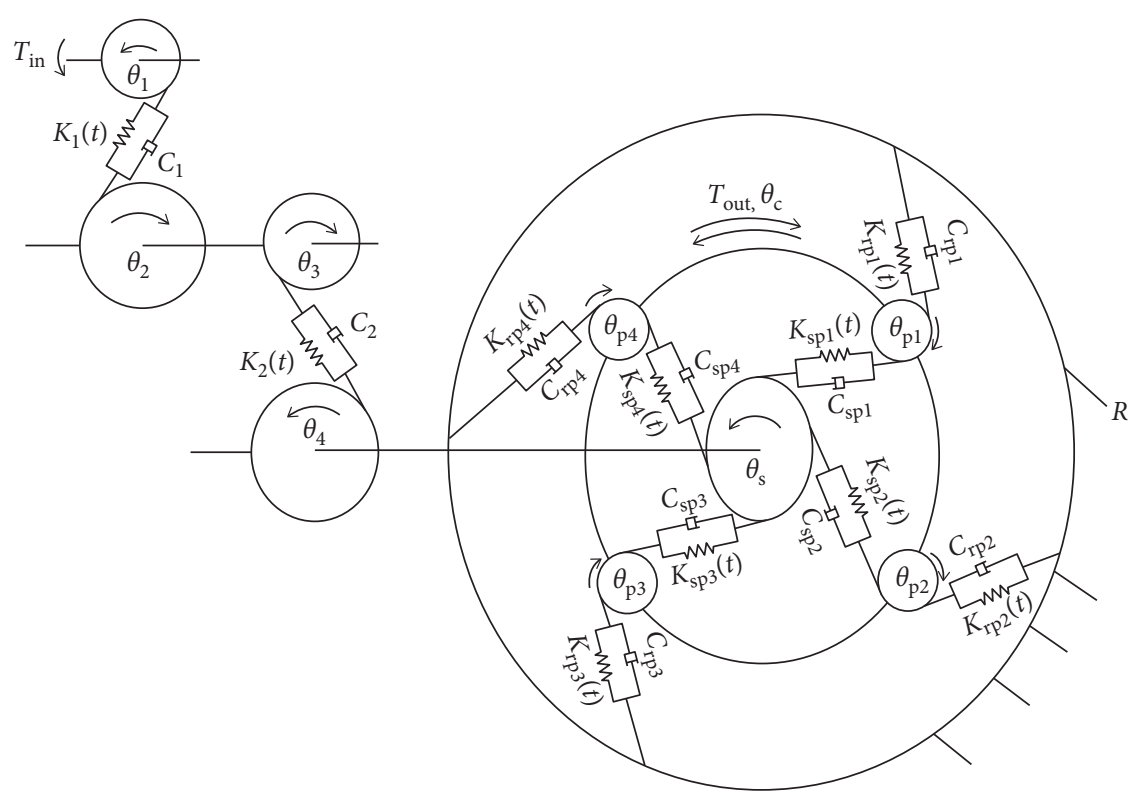

Figure 1: Torsional dynamic model of the multistage gear transmission system [18] (reproduced from Wang [18] (under the creative commons attribution license/public domain)).

mild wear in spur gears. Park et al. [20] presented an approximate method to predict the surface wear of hypoid gears using surface interpolation. In this paper, the clearance was controlled by changing the size of the dimensionless composite error amplitude $\bar{e}_{a i}[21]$. The bifurcation diagram of the multistage gear transmission system with the change in excitation frequency was calculated in the normal state. According to the clearance calculation formula given by the China national standard GB 2363-90, the dimensionless clearance interval of the meshing gear in the normal state is $[0.1,1]$.

\subsection{Nonlinear Dynamic Behavior Analysis of the System with Increased Gear Wear}

1.2.1. System Bifurcation Diagrams with Increased Gear Wear. By increasing the wear degree of fixed-axis spur gear 1 , the influence of fixed-axis gear wear on the excitation frequency range of the multistage gear transmission system was investigated. The minimum clearance of the multistage gear transmission system was selected as the initial state, that is, $\bar{e}_{\mathrm{a} i}=0.1$. At this point, the system is in a periodic motion state, and it is easy to observe the changes caused by the fixed-axis gear wear. The variable-step Runge-Kutta method was used to solve the nonlinear differential equations numerically (1). The bifurcation diagrams were investigated when the planetary gear clearance was constant $\left(\bar{e}_{\text {aspn }}=\bar{e}_{\text {arpn }}=0.1\right)$, and the fixed-axis clearance increased gradually $\left(\bar{e}_{\mathrm{a} 1}=\bar{e}_{\mathrm{a} 2}=0.1 \sim 1\right)$ on the meshing points of the $1^{\text {st }}$ stage fixed-axis gear and the planetary gear with the ring gear, as shown in Figure 2. The gear parameters of the multistage gear transmission system are shown in Table 1. The pressure angle $\alpha=20^{\circ}, T_{\text {in }}=6.5 \mathrm{~N} \cdot \mathrm{m}, T_{\text {out }}=8.5 \mathrm{~N} \cdot \mathrm{m}$, $b_{i}=5 \mu \mathrm{m}$, and the damping ratio of the meshing pairs $\xi_{i}=0.07$. These parameters were derived from the multistage gear transmission system test rig. We set the sampling interval as $\Omega_{1}=0.01: 0.01: 5$. Each $\Omega_{1}$ calculates 80 rotating periods. The number of samples for each rotating period was 256 points. The initial velocity and displacement were set to 0 . The calculation time of the bifurcation diagram was $2820 \mathrm{~s}$.

Figure 2(a) shows that the system is in a single-periodic motion state from the beginning and then changes from single-periodic motion to multiperiodic motion at $\Omega_{1}=1$. When $\Omega_{1}=3.5$, a quasi-periodic motion of the large oscillation occurs. When $\bar{e}_{\mathrm{a} 1}=\bar{e}_{\mathrm{a} 2}=0.2$ (Figure 2(c)), chaos occurs at $\Omega_{1}=1.5$. However, the chaos soon disappears and becomes periodic motion again. The large oscillation advances to $\Omega_{1}=3.2$. The wear continues to increase (Figure 2(e)), and the chaos range increases. The interval of $\Omega_{1} \in[0.5,1.6]$ is all chaotic. When $\bar{e}_{\mathrm{a} 1}=\bar{e}_{\mathrm{a} 2}=0.8$ (Figure $2(\mathrm{~g})$ ), the interval of $\Omega_{1} \in[0.5,0.85]$ degenerates into periodic motion. However, the vibration amplitude of the chaotic motion range $\Omega_{1} \in[0.85,1.6]$ increases dramatically. When $\bar{e}_{\mathrm{a} 1}=\bar{e}_{\mathrm{a} 2}=1$ (Figure 2(i)), the chaotic interval is $[0.9,1.6]$, and the chaotic amplitude increases further. The large oscillation range is in advance of the raising process of $\bar{e}_{\mathrm{a} 1}$, which is already $\Omega_{1}=2.3$.

On the meshing point of the planetary gear, the system is always in a state of periodic motion because of its small initial setting. When the fixed-axis gear clearance begins to increase, the motion state of the planetary gear is not affected (Figure 2(d)). The fixed-axis gear clearance continues to increase, the chaotic motion of the fixed-axis gear is transmitted to the planetary gear, and the planetary gear also presents a small chaotic characteristic (Figure 2(f)). When the fixed-axis gear clearance continues to increase, the amplitude of the fixed-axis gear chaotic motion increases significantly, leading to the synchronous 


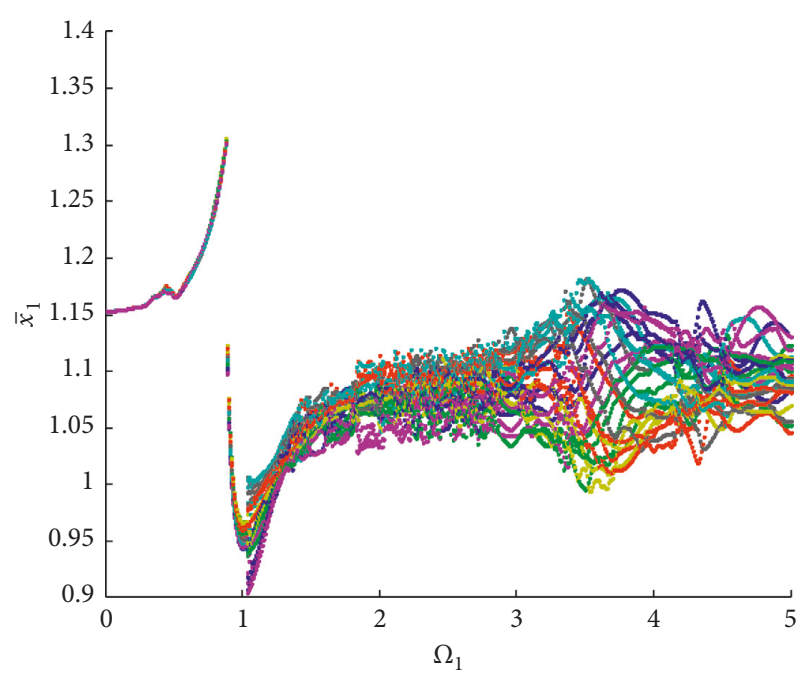

(a)

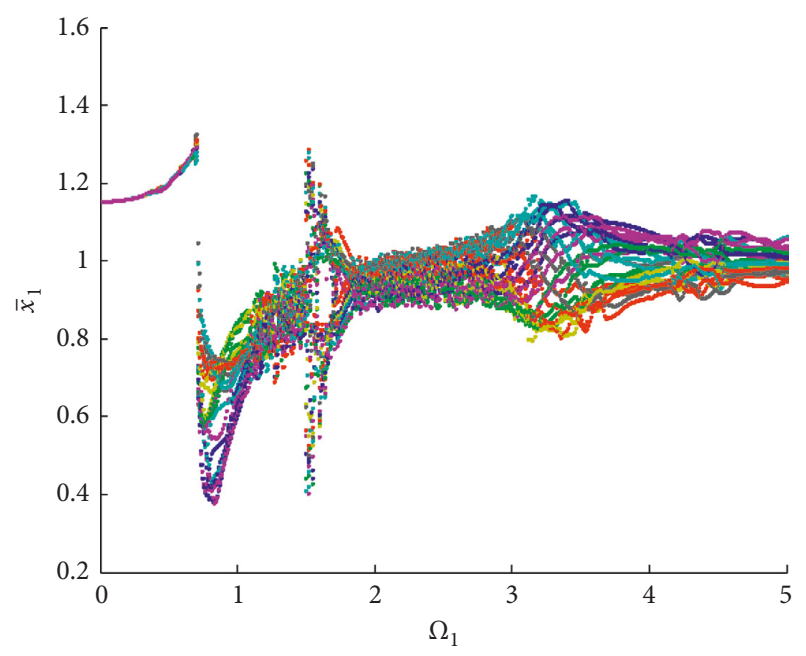

(c)

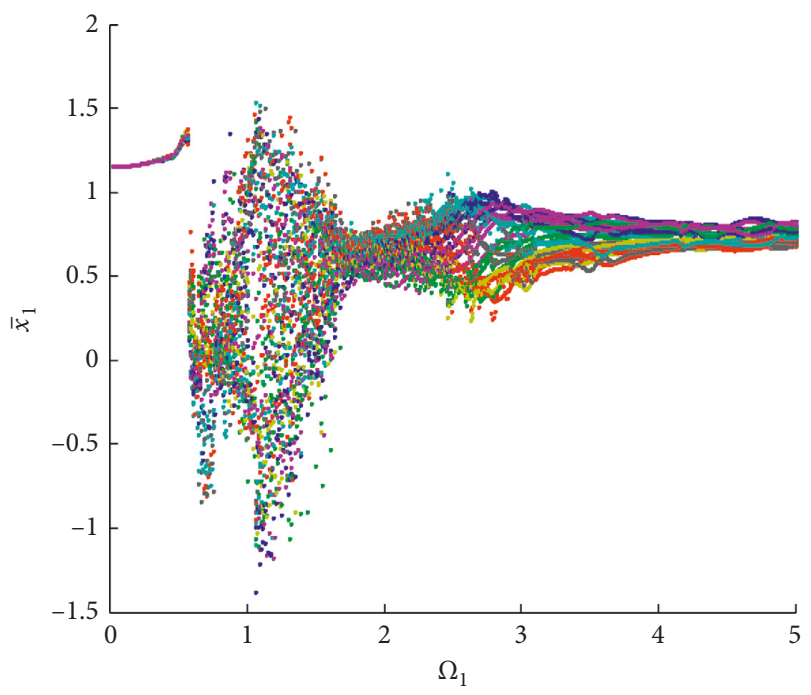

(e)

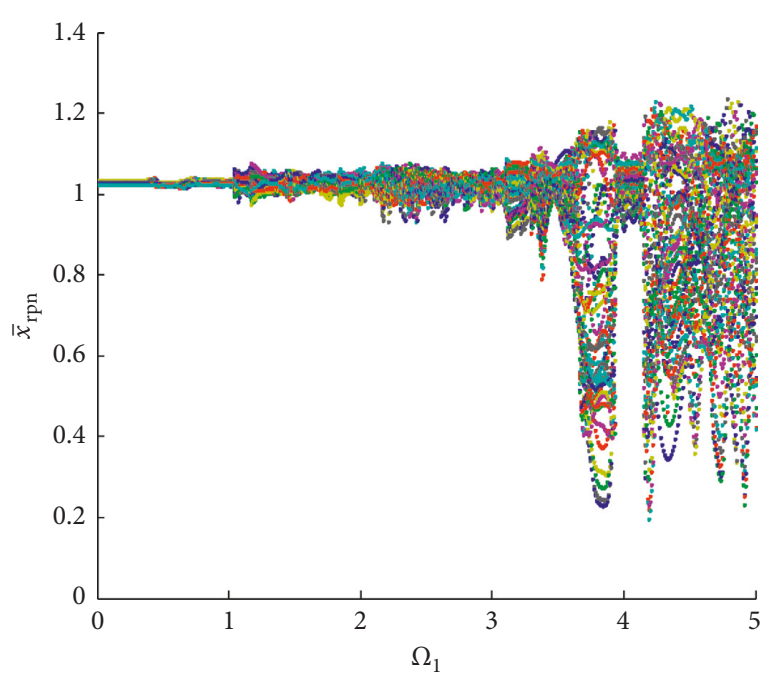

(b)

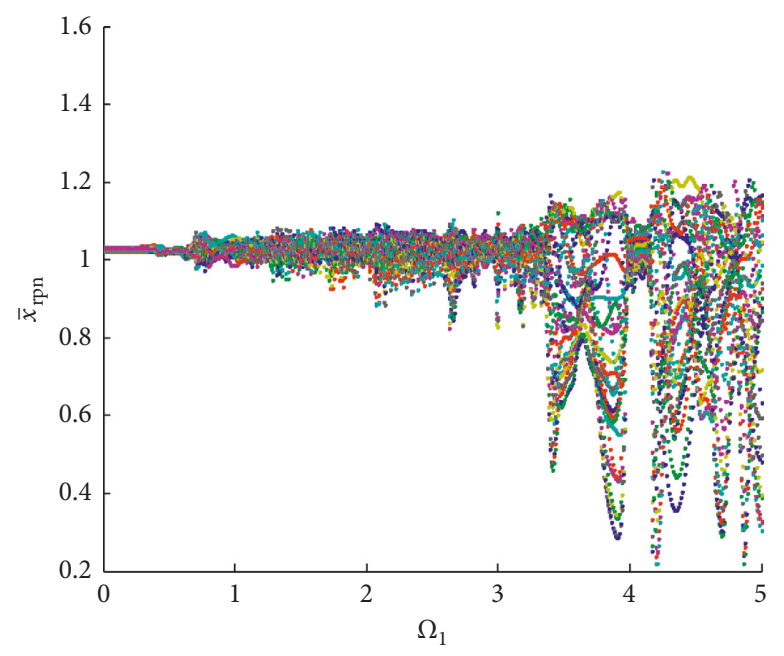

(d)

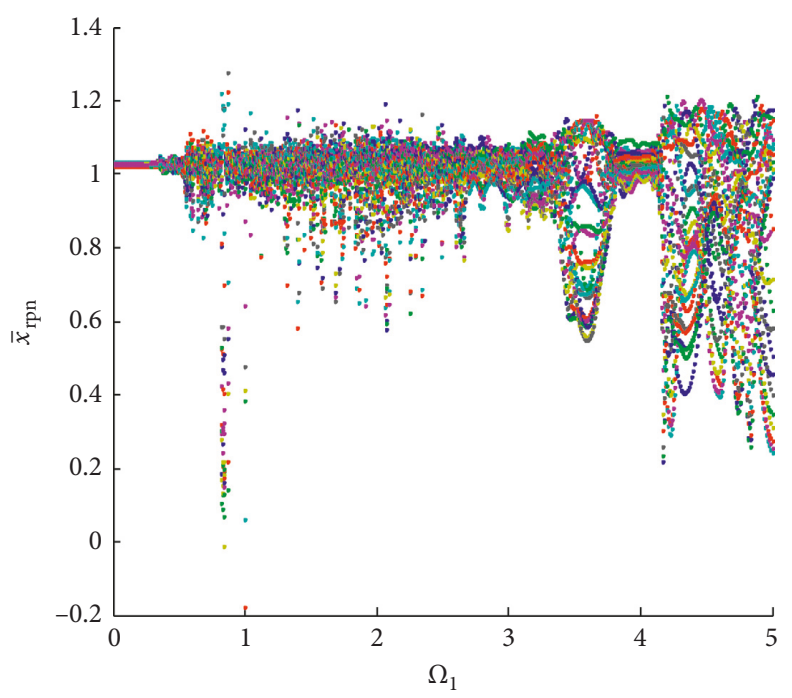

(f)

Figure 2: Continued. 


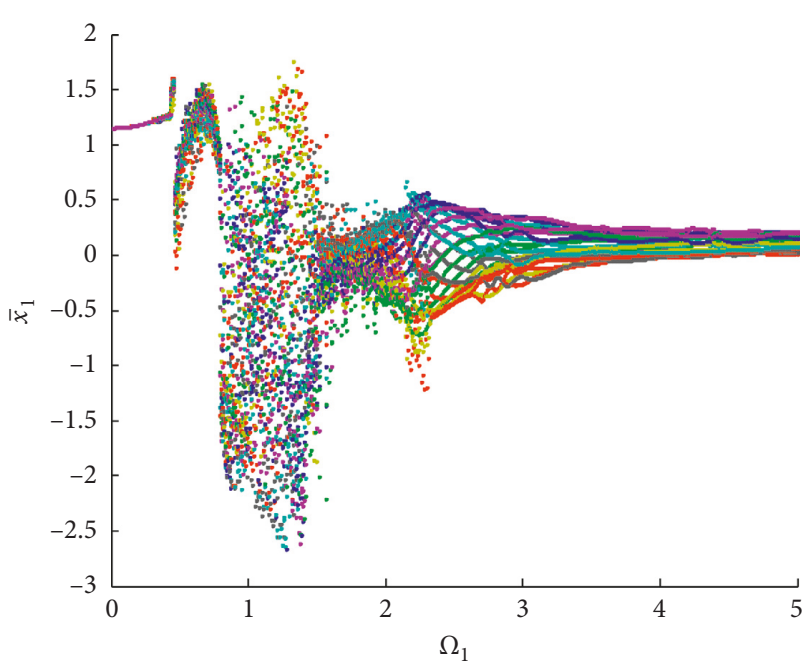

(g)

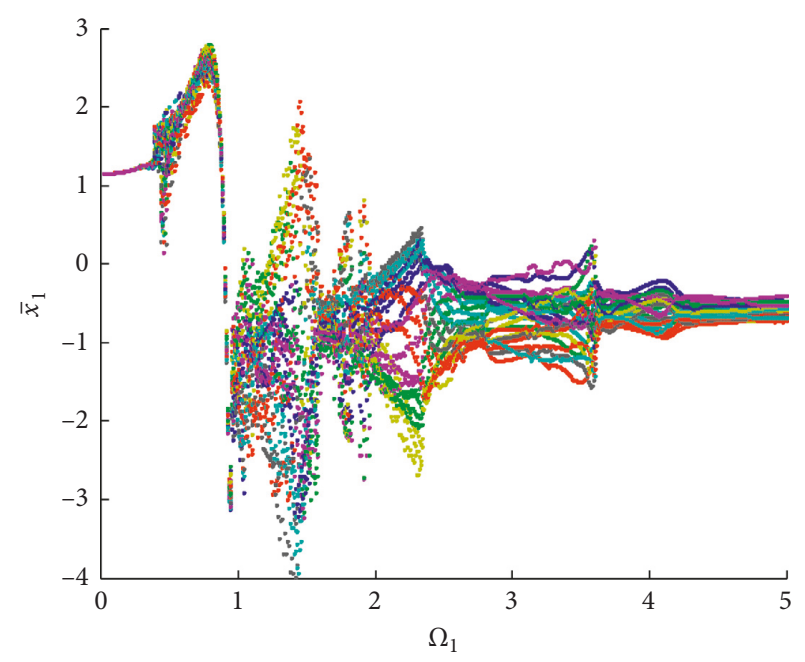

(i)

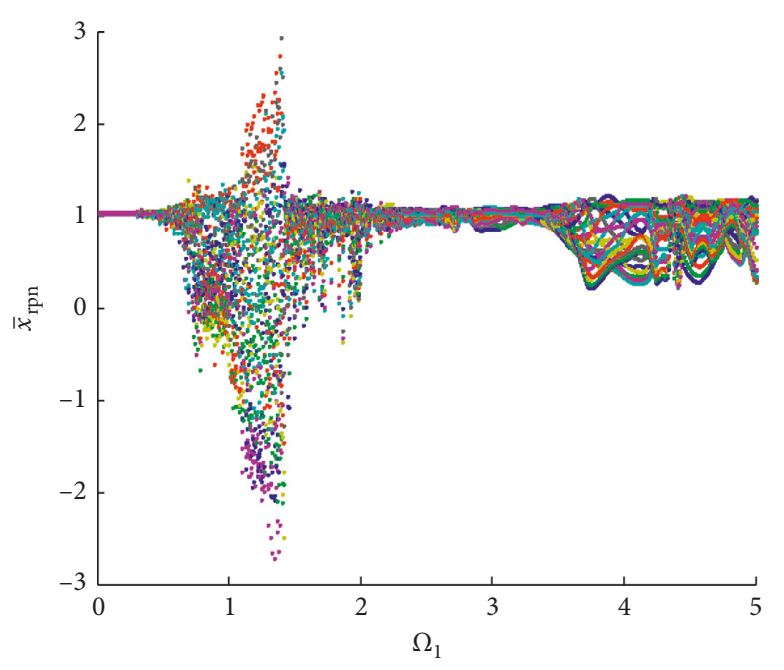

(h)

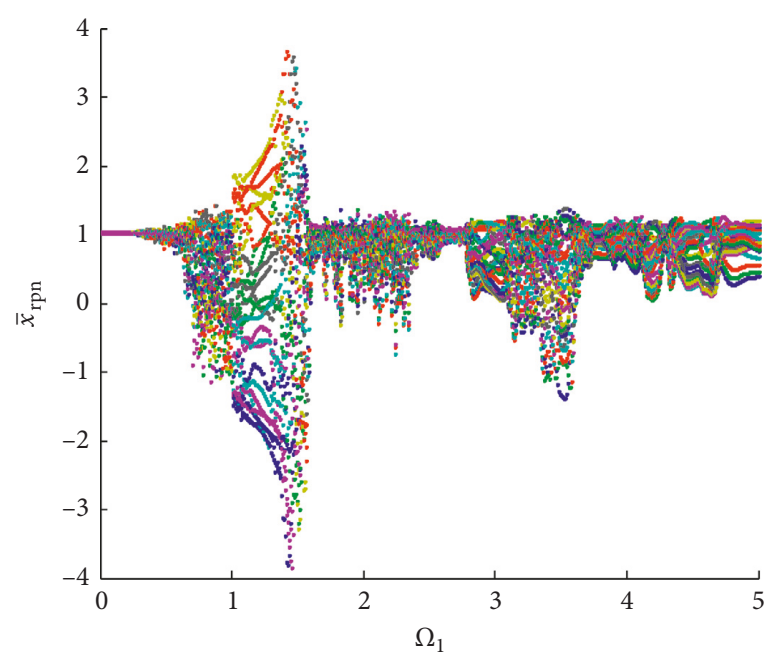

(j)

Figure 2: Bifurcation diagrams of the system with fixed-axis wear fault: (a) and (b) $\bar{e}_{\mathrm{a} 1}=\bar{e}_{\mathrm{a} 2}=0.1$; (c) and (d) $\bar{e}_{\mathrm{a} 1}=\bar{e}_{\mathrm{a} 2}=0.2$; (e) and (f) $\bar{e}_{\mathrm{a} 1}=\bar{e}_{\mathrm{a} 2}=0.4 ;(\mathrm{g})$ and (h) $\bar{e}_{\mathrm{a} 1}=\bar{e}_{\mathrm{a} 2}=0.8 ;(\mathrm{i})$ and $(\mathrm{j}) \bar{e}_{\mathrm{a} 1}=\bar{e}_{\mathrm{a} 2}=1$.

TABle 1: Gear parameters.

\begin{tabular}{|c|c|c|c|c|c|c|}
\hline Gear & Number of teeth & $R_{\mathrm{r} i}(\mathrm{~mm})$ & $R_{\mathrm{b} i}(\mathrm{~mm})$ & Mass $\left(\mathrm{m}_{i} / \mathrm{g}\right)$ & $J_{i}\left(\mathrm{~g} \cdot \mathrm{m}^{2}\right)$ & Face width $(\mathrm{mm})$ \\
\hline 1 & 29 & 19.2 & 20.4 & 125 & 0.05 & 30 \\
\hline 2 & 100 & 68.9 & 70.5 & 1224.5 & 6 & 30 \\
\hline 3 & 36 & 23.9 & 25.3 & 224 & 0.14 & 30 \\
\hline 4 & 90 & 61.5 & 63.4 & 1111 & 4 & 20 \\
\hline$s$ & 28 & 12.3 & 13 & 41 & 0.007 & 20 \\
\hline pn & 36 & 16 & 17 & 34.6 & 0.01 & 20 \\
\hline c & & & 30 & 848.7 & 0.76 & 20 \\
\hline $\mathrm{R}$ & 100 & 45.6 & 47 & & & 20 \\
\hline
\end{tabular}

chaotic motion of the planetary gear in the interval of $\Omega_{1} \in[0.85,1.6]$ (Figure 2(h)). In Figure 2(j), the planetary gear and the fixed-axis gear show synchronization in the chaotic motion and periodic oscillation interval. At this time, the planetary gear is mainly affected by the fixed-axis gear vibration, and it reflects the vibration characteristics of the fixed-axis gears.

Figure 2 shows that the increased gear clearance of the fixed axis mainly affects the excitation frequency range of $[0.5,1.6]$ showing that the vibration of the system in this 
interval is mainly affected by the characteristics of the fixedaxis gear. The clearance of the planetary gear mainly influences the interval where the excitation frequency is greater than 3, and this result has been described in another paper by the author in [22].

\subsubsection{Frequency Characteristics of the Fixed-Axis Gear under} Different Excitation Frequencies. Section 1.2.1 shows that with the increase in the clearance, the system changes from single-periodic motion to multiperiodic, chaos, and quasiperiodic motions. To understand the fault frequency characteristics of the system in each motion state, more detailed analyses of the time domain, the frequency domain, the phase diagram, and the Poincaré section of each motion state are required. The large clearance state is (Figure $2(\mathrm{~g})$ ) selected as the study object. At this time, the system includes all types of motion states. The wear failure is relatively serious, and the characteristics are more obvious. The dimensionless gear characteristic frequencies in the multistage gear transmission system are shown in Table 2.

In Figure 2(g), when $\bar{e}_{\mathrm{a} 1}=\bar{e}_{\mathrm{a} 2}=0.8$, the time-domain diagrams, frequency-domain diagrams, phase diagrams, and Poincaré section diagrams of the $1^{\text {st }}$ stage fixed-axis gear are calculated on each excitation frequency to obtain Figures 3-14.

As shown in Figure 3, when the excitation frequency is very low, the system is in single-periodic motion. The amplitude of vibration is very small. The Poincaré section is a point. There is only one frequency component in the spectrum, that is, the $1^{\text {st }}$ stage meshing frequency $f_{1}$. As the excitation frequency increases (Figures 4 and 5), the system enters multiperiodic motion. The time-domain vibration amplitude increases. The Poincaré section changes from a point to double ellipses. Since the periodic motion is maintained, the frequency component is still $1^{\text {st }}$ stage meshing frequency $f_{1}$, and the frequency amplitude increases significantly. As the excitation frequency continues to increase (Figures 6-9(c)), the system moves from multiperiodic motion to chaos due to increased collision motion. In the spectrum shown in Figures 6$9(\mathrm{~d})$, the $2^{\text {nd }}$ stage meshing frequency $f_{2}$ appears. Then, the chaotic motion enters the limit cycle through Hopf bifurcation, as shown in Figures 10-12(c). As the excitation frequency continues to increase, the system maintains a quasi-periodic motion state (limit cycle state) and presents torus doubling (Figures 13 and 14(c)). The amplitude of the $1^{\text {st }}$ stage meshing frequency $f_{1}$ is held constant in the spectrum, and the amplitude of the $2^{\text {nd }}$ stage meshing frequency $f_{2}$ gradually decreases (Figures 13 and $14(\mathrm{~d}))$.

When the clearance of the fixed-axis gear increases, the chaotic motion of the system is caused by the collision, and the fault feature of the $2^{\text {nd }}$ stage meshing frequency appears in the spectrum. The clearance size determines the speed of the system entering chaos. The larger the clearance is, the faster the system moves into the chaotic motion state and the faster the system will degenerate from chaos to quasiperiodic motion. The wear degree of the system can be monitored through the motion state and frequency characteristics of the system to predict the system wear fault in advance.

1.3. Test Signal Identification and Diagnosis. Figure 15 shows a multistage gear transmission test rig consisting of a twostage fixed-axis gear and a one-stage planetary gear.

According to the actual rotation speed of the motor, the operating state occurs when the excitation frequency $\Omega_{1}=1$ (corresponding to a motor frequency of $30 \mathrm{~Hz}$ ) is selected. Signal testing and analysis were performed on the test rig. The parameters are shown in Table 1. To facilitate comparison with simulation results, the measured spectrum is dimensionless. Figure 16 shows the dimensionless spectrum of the axial measuring point on the drive side of the fixedaxis gearbox when $\Omega_{1}=1$. The dimensionless characteristic frequencies of the gears in the multistage gear transmission system are shown in Table 2.

Comparing Figure 16 with Figure 6(d) reveals that the main peaks of the two spectra are similar: all are $f_{1}, f_{2}$, and $2 f_{2}$. In Figure 16 , the planetary gear meshing frequency $f_{3}$ is larger, indicating that the planetary gear clearance is more than $0.1\left(\bar{e}_{\text {aspn }}=\bar{e}_{\text {arpn }}>0.1\right)$ at this time. Due to the obvious amplitude of $f_{2}$, the motion state of the fixed-axis gear is initially judged to be chaotic motion, and the clearance condition is $\bar{e}_{\mathrm{a} 1}=\bar{e}_{\mathrm{a} 2}=0.8$. However, according to Figures 2(e), 2(g), and 2(i), when the excitation frequency is 1 , the interval $[0.4,1]$ is chaotic; thus, it is necessary to perform more detailed spectrum analysis (Figure 17) to determine the degree of wear.

Figure 17 shows that the main peaks are $f_{1}$ and $(1 / 2) f_{1}$ when $\bar{e}_{\mathrm{a} 1}=\bar{e}_{\mathrm{a} 2}=0.4-0.5$. For $\bar{e}_{\mathrm{a} 1}=\bar{e}_{\mathrm{a} 2}=0.6-1$, the main peaks are $f_{1}, f_{2}$, and $2 f_{2}$. The amplitudes of $f_{2}$ and $2 f_{2}$ are relatively stable, but the amplitude of $f_{1}$ increases as the clearance increases. According to the proportional relationship between the amplitudes of $f_{1}$ and $f_{2}$ in Figure 16, the degree of wear failure is predicted to be approximately 0.8-0.9.

An open-case inspection of the test rig revealed that there was severe wear on the $1^{\text {st }}$ stage fixed-axis gears (Figure 18), and the gear clearance was $e_{\mathrm{a} 1} \approx 4 \mu \mathrm{m}$. This conclusion is the same conclusion that was reached in the theoretical study.

\section{Conclusions}

The wear degree of the fixed-axis gear in a test rig was judged based on the frequency spectrum characteristics of the wear fault. By changing the fixed-axis gear clearance, the wear failure of the fixed-axis gear was simulated, and the bifurcation diagrams of the fixed-axis gear with different clearances were analyzed. The changes of the motion state of the system were investigated. The vibration mechanism of the system with wear failure was summarized. The study found that the wear failure of the fixed-axis gear mainly affects the excitation frequency range of $[0.5,1.6]$. With the increase in wear, the periodic motion of the system becomes chaotic. The more serious the wear is, the more the chaotic 
TABle 2: Dimensionless characteristic frequencies of the multistage gear transmission system (Hz).

Characteristic frequency Dimensional frequency

Meshing frequency of the 1st stage fixed-axis gear $f_{1}$

Meshing frequency of the 2 nd stage fixed-axis gear $f_{2}$

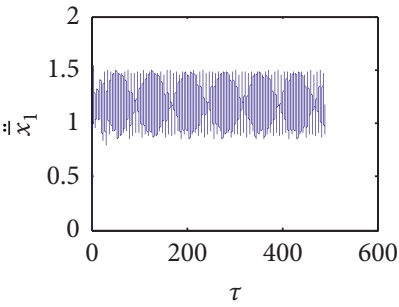

(a)

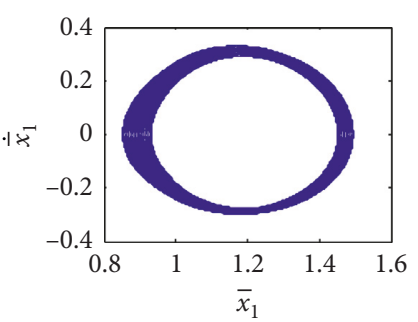

(b)

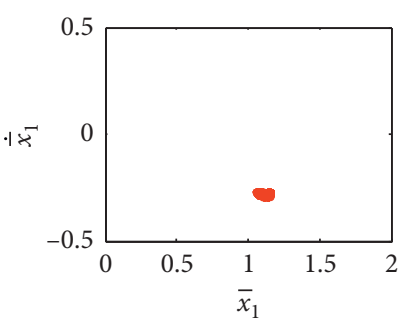

(c)

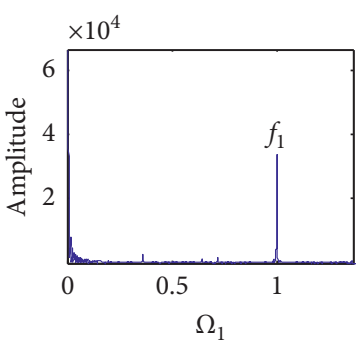

(d)

FIgURE 3: Vibration characteristics when $\Omega_{1}=0.3$ : (a) time domain, (b) phase diagram, (c) Poincaré section, and (d) frequency domain.

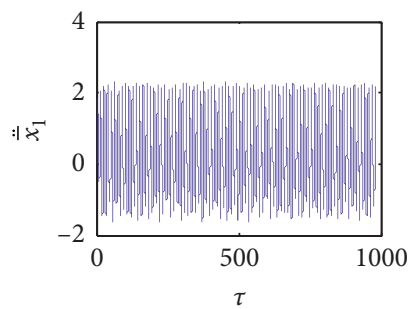

(a)

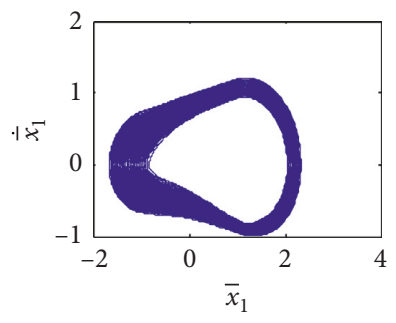

(b)

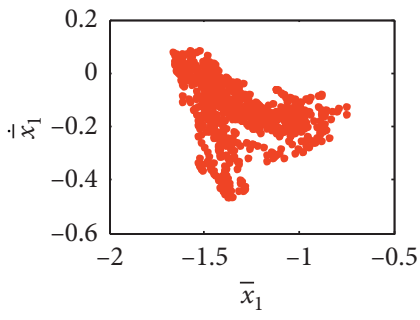

(c)

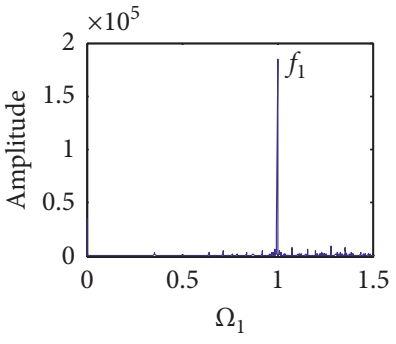

(d)

Figure 4: Vibration characteristics when $\Omega_{1}=0.5$ : (a) time domain, (b) phase diagram, (c) Poincaré section, and (d) frequency domain.

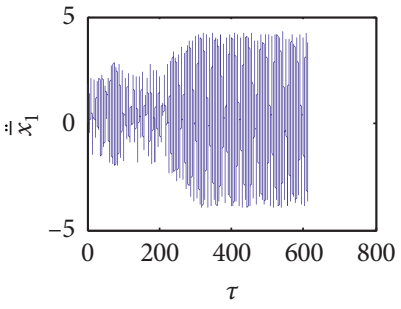

(a)

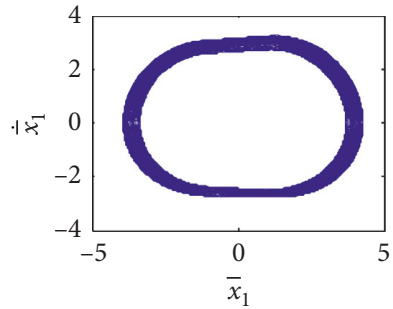

(b)

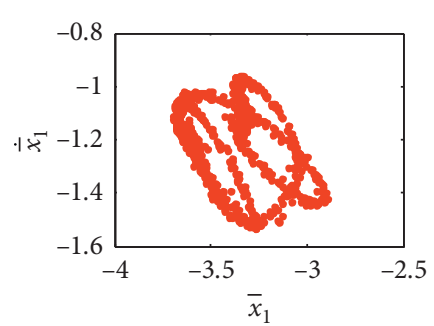

(c)

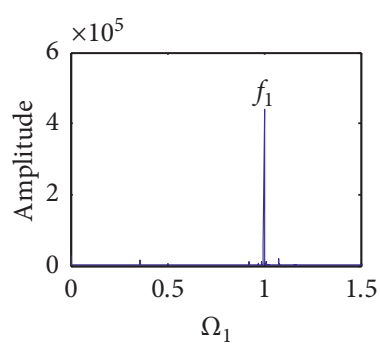

(d)

Figure 5: Vibration characteristics when $\Omega_{1}=0.8$ : (a) time domain, (b) phase diagram, (c) Poincaré section, and (d) frequency domain.

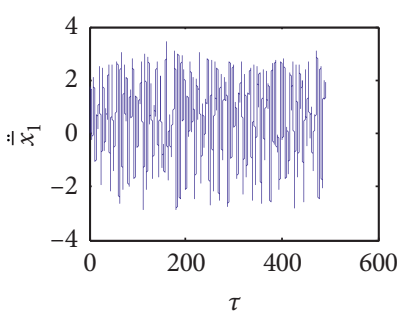

(a)

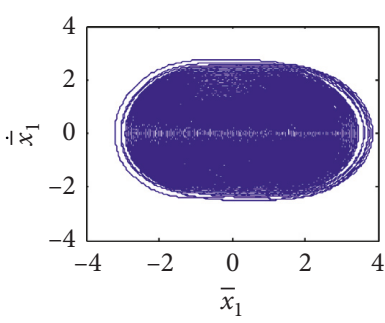

(b)

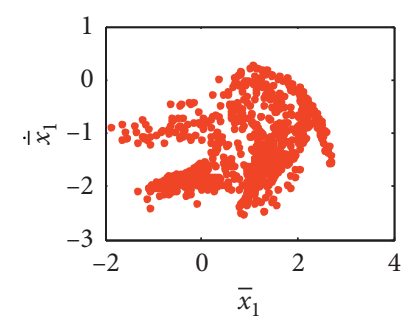

(c)

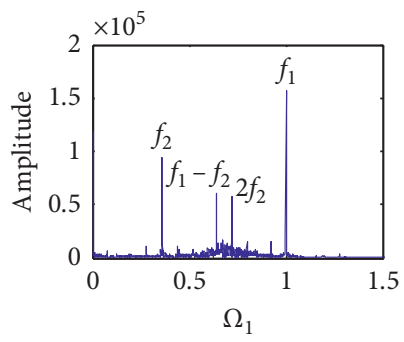

(d)

FIGURE 6: Vibration characteristics when $\Omega_{1}=1$ : (a) time domain, (b) phase diagram, (c) Poincaré section, and (d) frequency domain. 


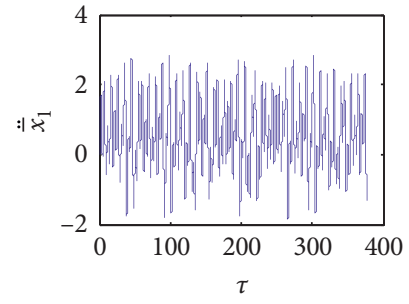

(a)

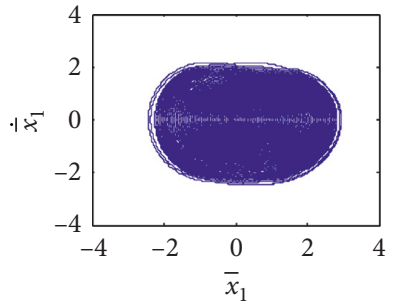

(b)

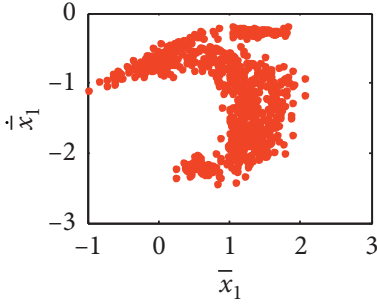

(c)

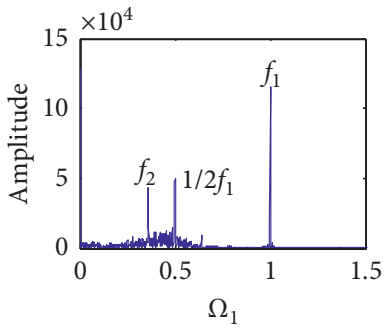

(d)

FIgURE 7: Vibration characteristics when $\Omega_{1}=1.3$ : (a) time domain, (b) phase diagram, (c) Poincaré section, and (d) frequency domain.

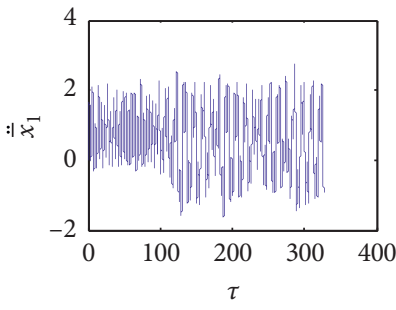

(a)

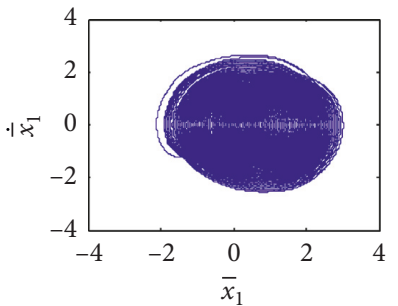

(b)

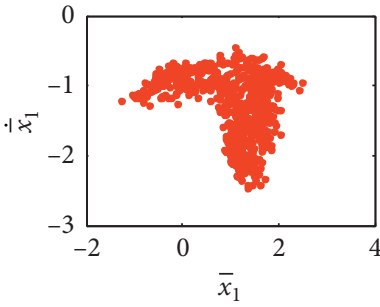

(c)

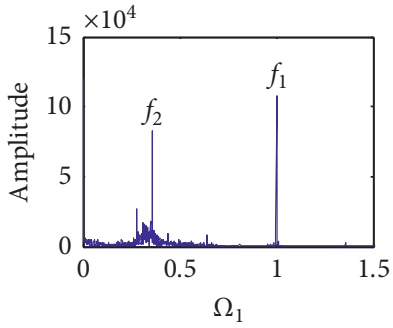

(d)

Figure 8: Vibration characteristics when $\Omega_{1}=1.5$ : (a) time domain, (b) phase diagram, (c) Poincaré section, and (d) frequency domain.

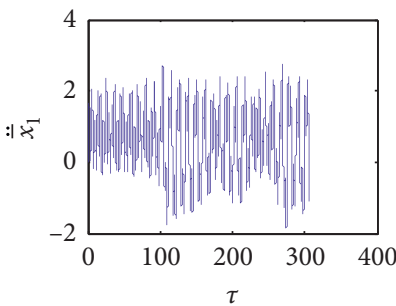

(a)

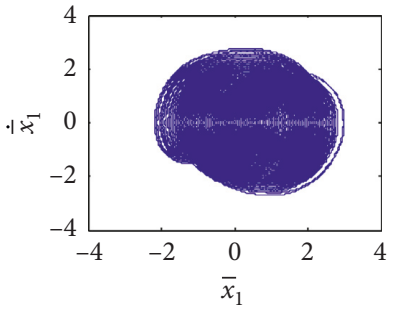

(b)

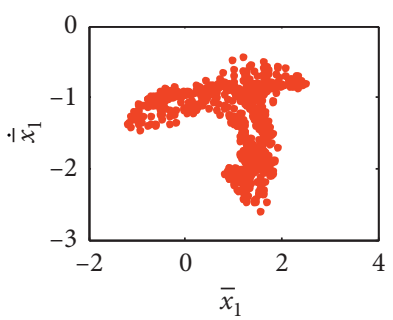

(c)

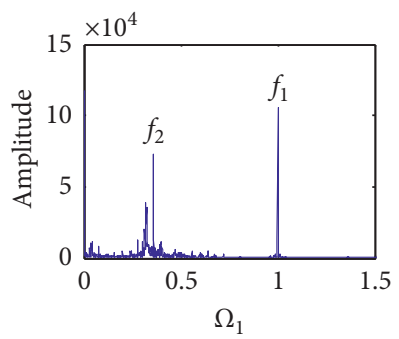

(d)

Figure 9: Vibration characteristics when $\Omega_{1}=1.6$ : (a) time domain, (b) phase diagram, (c) Poincaré section, and (d) frequency domain.

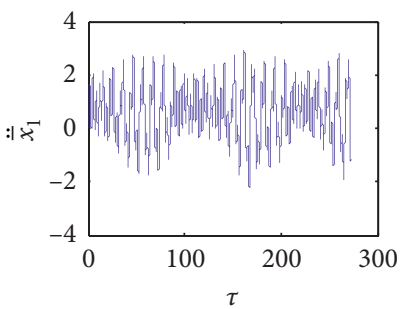

(a)

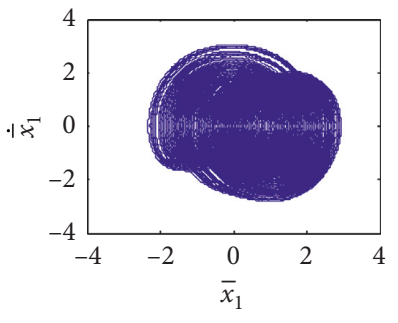

(b)

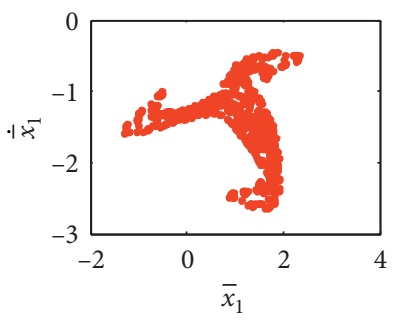

(c)

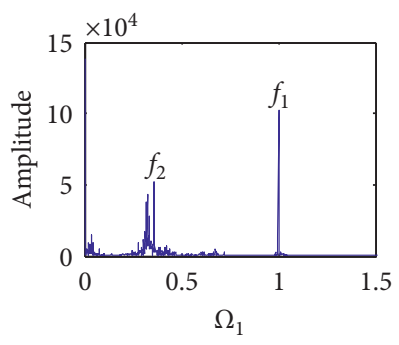

(d)

Figure 10: Vibration characteristics when $\Omega_{1}=1.8$ : (a) time domain, (b) phase diagram, (c) Poincaré section, and (d) frequency domain.

motion advances. By studying the time domain, frequency domain, phase diagram, and Poincaré section of each motion state when there is a large clearance, the transition processes and frequency characteristics of each motion state were analyzed. The fault frequency characteristics of the wear faults were obtained. 


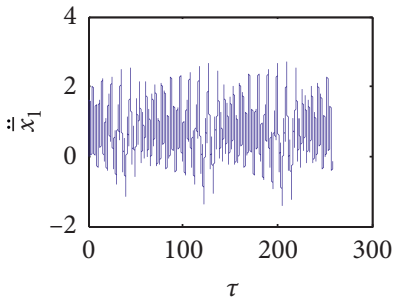

(a)

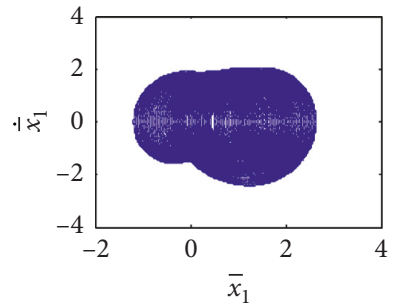

(b)

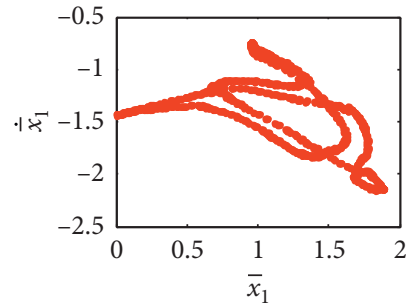

(c)

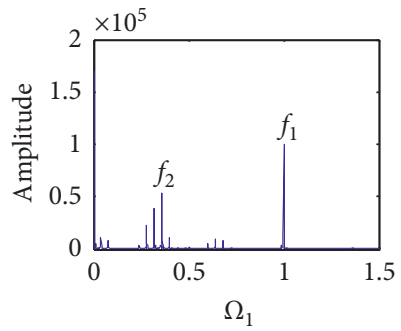

(d)

Figure 11: Vibration characteristics when $\Omega_{1}=1.9$ : (a) time domain, (b) phase diagram, (c) Poincaré section, and (d) frequency domain.

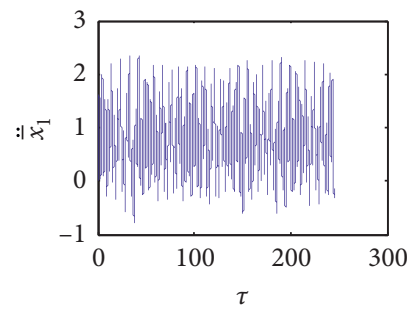

(a)

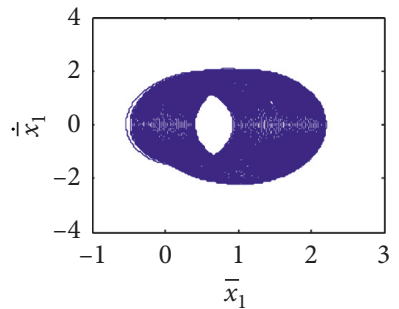

(b)

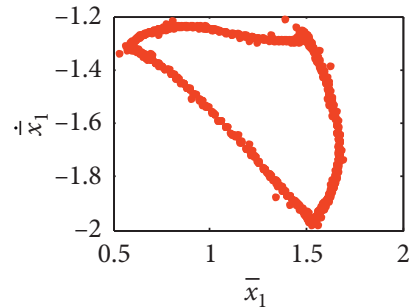

(c)

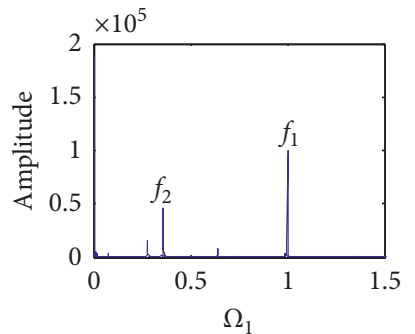

(d)

Figure 12: Vibration characteristics when $\Omega_{1}=2$ : (a) time domain, (b) phase diagram, (c) Poincaré section, and (d) frequency domain.

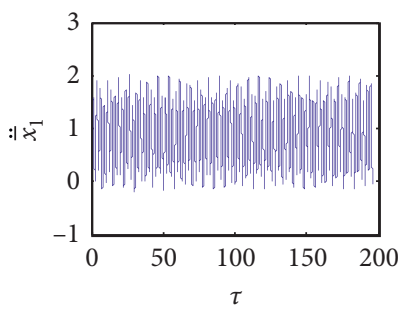

(a)

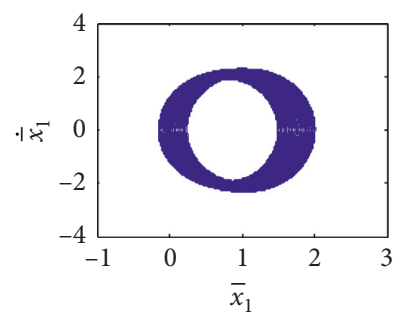

(b)

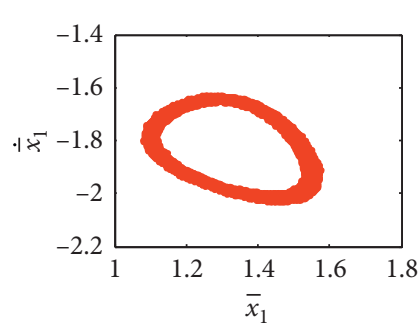

(c)

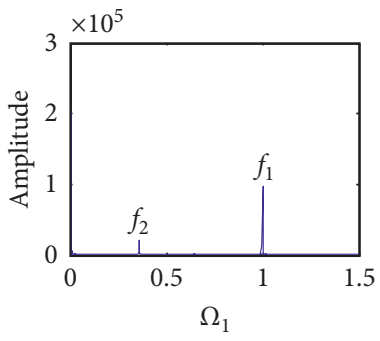

(d)

FIgURE 13: Vibration characteristics when $\Omega_{1}=2.5$ : (a) time domain, (b) phase diagram, (c) Poincaré section, and (d) frequency domain.

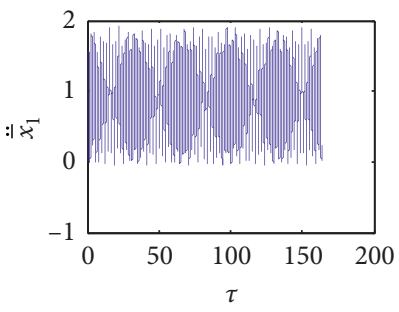

(a)

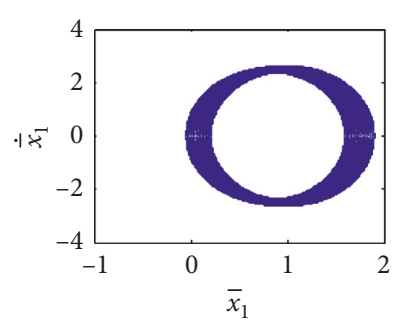

(b)

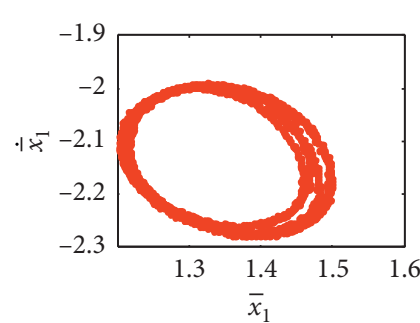

(c)

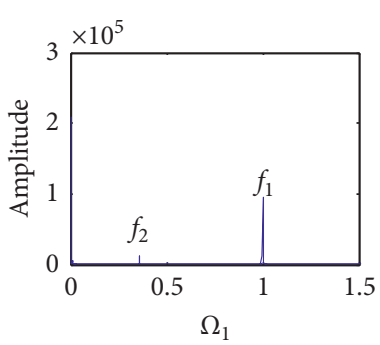

(d)

Figure 14: Vibration characteristics when $\Omega_{1}=3$ : (a) time domain, (b) phase diagram, (c) Poincaré section, and (d) frequency domain.

Using a test signal from the test rig at a certain excitation frequency, the motion state of the system was determined based on the motion state characteristics in the theoretical results, and the wear degree of the gear was roughly inferred. Then, the frequency spectra of different wear degrees were compared at the excitation frequency. Finally, the degree of 


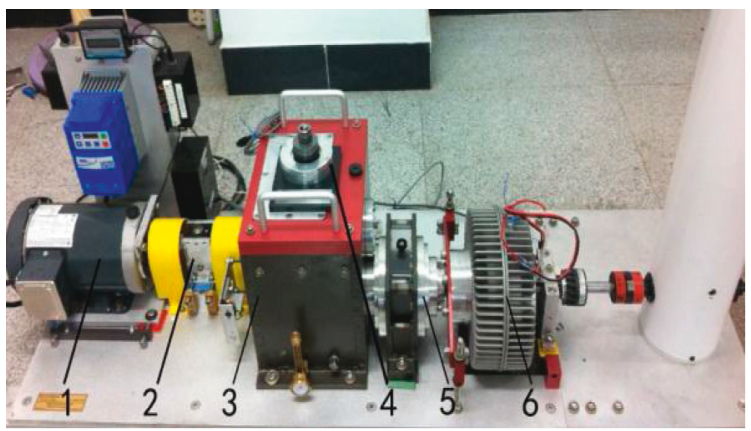

FIGURE 15: The multistage gear transmission system test rig. 1: motor; 2: torque sensor and encoder; 3: two-stage fixed-axis gearbox; 4: radial bearing load; 5: one-stage planetary gearbox; 6: brake [18] (reproduced from Wang [18] (under the creative commons attribution license/ public domain)).

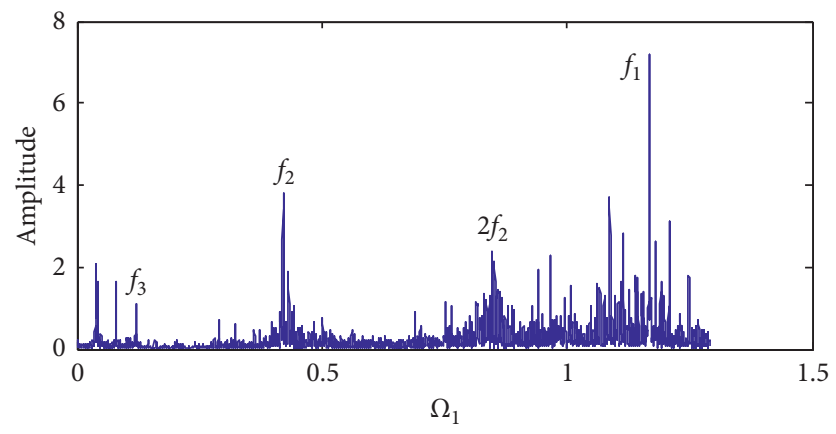

Figure 16: Dimensionless test signal frequency spectrum.

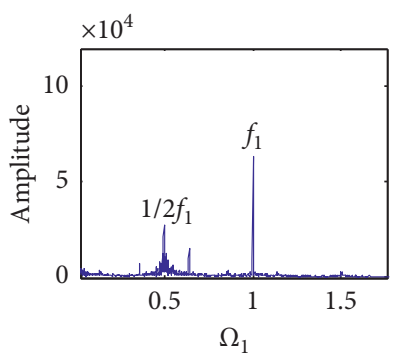

(a)

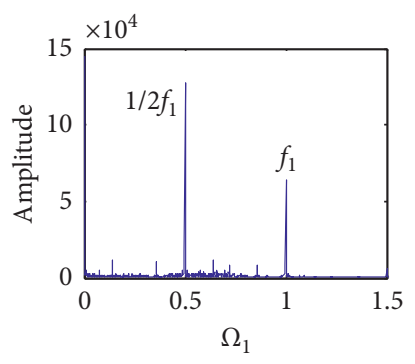

(b)

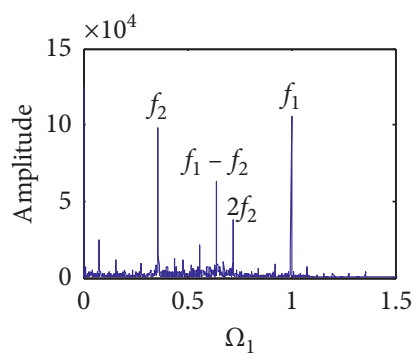

(c)

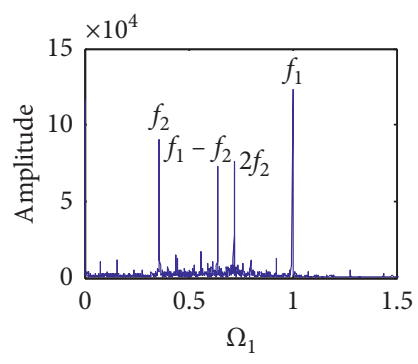

(d)

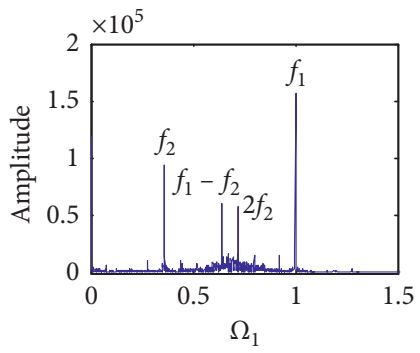

(e)

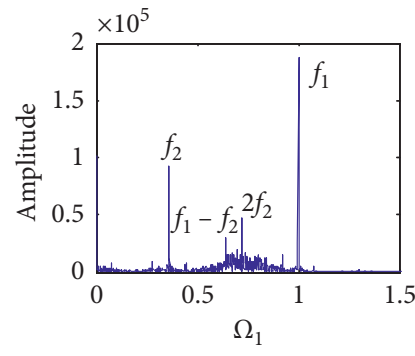

(f)

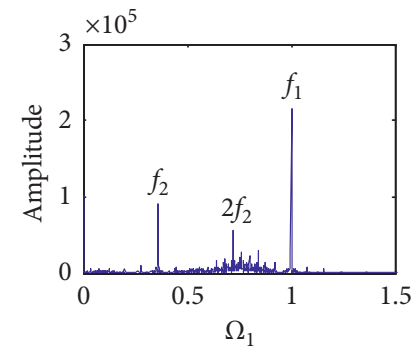

(g)

FIGURE 17: Frequency spectra for each clearance when $\Omega_{1}=1$ : (a) $\bar{e}_{\mathrm{a} 1}=\bar{e}_{\mathrm{a} 2}=0.4$, (b) $\bar{e}_{\mathrm{a} 1}=\bar{e}_{\mathrm{a} 2}=0.5$, (c) $\bar{e}_{\mathrm{a} 1}=\bar{e}_{\mathrm{a} 2}=0.6,(\mathrm{~d}) \bar{e}_{\mathrm{a} 1}=\bar{e}_{\mathrm{a} 2}=0.7,(\mathrm{e})$ $\bar{e}_{\mathrm{a} 1}=\bar{e}_{\mathrm{a} 2}=0.8$, (f) $\bar{e}_{\mathrm{a} 1}=\bar{e}_{\mathrm{a} 2}=0.9$, and $(\mathrm{g}) \bar{e}_{\mathrm{a} 1}=\bar{e}_{\mathrm{a} 2}=1$. 


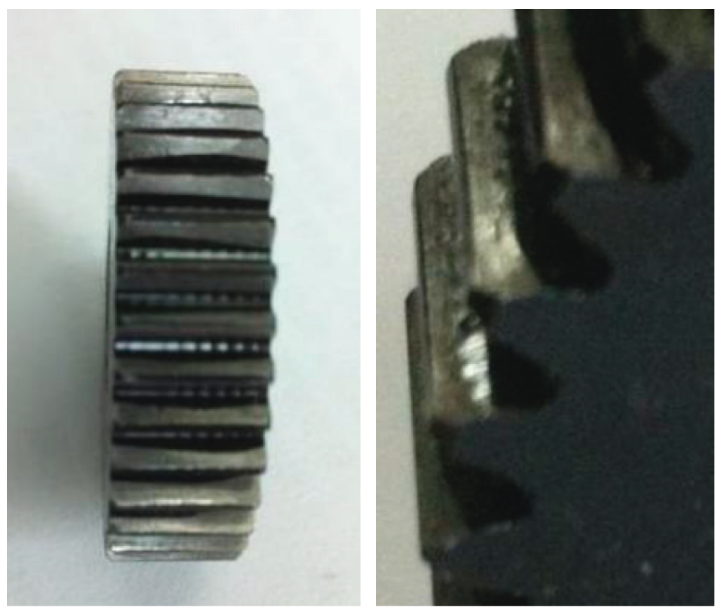

FIgURE 18: Fixed-axis wear failure gear.

wear of the test rig gears was determined. The experimental results were the same as the theoretical results.

\section{Data Availability}

The data used to support the findings of this study are included within the article.

\section{Conflicts of Interest}

The author declares no conflicts of interest.

\section{Acknowledgments}

The author gratefully acknowledges the financial support from Baoji Science and Technology Plan Project (2017JH210).

\section{References}

[1] Z. M. Fan and H. X. Yang, "Research on friction and wear of gear transmission with meshed medium belt," Advanced Materials Research, vol. 753-755, pp. 1719-1722, 2013.

[2] V. Onishchenko, "Investigation of tooth wears from scuffing of heavy duty machine spur gears," Mechanism and Machine Theory, vol. 83, pp. 38-55, 2015.

[3] J. A. Brandão, P. Cerqueira, J. H. O. Seabra, and M. J. D. Castro, "Measurement of mean wear coefficient during gear tests under various operating conditions," Tribology International, vol. 102, pp. 61-69, 2016.

[4] M. Ş Tunalioğlu and B. Tuç, "Theoretical and experimental investigation of wear in internal gears," Wear, vol. 309, no. 12, pp. 208-215, 2014.

[5] M. Masjedi and M. M. Khonsari, "On the prediction of steadystate wear rate in spur gears," Wear, vol. $342-343$, pp. 234243, 2015.

[6] A. C. Petare and N. K. Jain, "On simultaneous improvement of wear characteristics, surface finish and microgeometry of straight bevel gears by abrasive flow finishing process," Wear, vol. 404-405, pp. 38-49, 2018.

[7] J. Wojnarowski and V. Onishchenko, "Tooth wear effects on spur gear dynamics," Mechanism and Machine Theory, vol. 38, no. 2, pp. 161-178, 2003.
[8] Z. Liu, Z. Liu, J. Zhao, and G. Zhang, "Study on interactions between tooth backlash and journal bearing clearance nonlinearity in spur gear pair system," Mechanism and Machine Theory, vol. 107, pp. 229-245, 2017.

[9] H. Ding and A. Kahraman, "Interactions between nonlinear spur gear dynamics and surface wear," Journal of Sound and Vibration, vol. 307, no. 3-5, pp. 662-679, 2007.

[10] T. Osman and Ph. Velex, "Static and dynamic simulations of mild abrasive wear in wide-faced solid spur and helical gears," Mechanism and Machine Theory, vol. 45, no. 6, pp. 911-924, 2010.

[11] Y. J. Shen, S. P. Yang, H. J. Xing, and X. Y. Wang, "Nonlinear dynamics of a spur gear pair with fault," Key Engineering Materials, vol. 353-358, pp. 1177-1180, 2007.

[12] R. Zhang, F. Gu, H. Mansaf, T. Wang, and A. D. Ball, "Gear wear monitoring by modulation signal bispectrum based on motor current signal analysis," Mechanical Systems and Signal Processing, vol. 94, pp. 202-213, 2017.

[13] K. F. Brethee, D. Zhen, F. Gu, and A. D. Ball, "Helical gear wear monitoring: modelling and experimental validation," Mechanism and Machine Theory, vol. 117, pp. 210-229, 2017.

[14] H. Tian, X. Y. Kang, Y. J. Li, and J. N. Zhang, "Fault diagnosis of gear wearing based on order cepstrum analysis," Applied Mechanics and Materials, vol. 543-547, pp. 922-925, 2014.

[15] M. A. Plint and A. F. Alliston-Greiner, "The energy pulse: a new wear criterion and its relevance to wear in gear teeth and automotive engine valve trains," Lubrication Science, vol. 8, no. 3, pp. 233-251, 1996.

[16] Q. B. He, "Time-frequency manifold for nonlinear feature extraction in machinery fault diagnosis," Mechanical Systems and Signal Processing, vol. 35, no. 1-2, pp. 200-218, 2013.

[17] X. Liu, Y. Yang, and J. Zhang, "Investigation on coupling effects between surface wear and dynamics in a spur gear system," Tribology International, vol. 101, pp. 383-394, 2016.

[18] X. Wang, "Stability research of multistage gear transmission system with crack fault," Journal of Sound and Vibration, vol. 434, pp. 63-77, 2018.

[19] A. Flodin and S. Andersson, "Simulation of mild wear in spur gears," Wear, vol. 207, no. 1-2, pp. 16-23, 1997.

[20] D. Park, M. Kolivand, and A. Kahraman, "An approximate method to predict surface wear of hypoid gears using surface interpolation," Mechanism and Machine Theory, vol. 71, pp. 64-78, 2014.

[21] Y. G. Wang, H. Q. Zheng, T. Q. Yang, Z. Z. Guan, and J. Yang, "Nonlinear dynamics behavior of gear system with fault parameters," Journal of Vibration, Measurement \& Diagnosis, vol. 31, no. 5, pp. 570-573, 2011.

[22] X. Wang, "A study on coupling faults' characteristics of fixedaxis gear crack and planetary gear wear," Shock and Vibration, vol. 2018, Article ID 4692796, 13 pages, 2018. 


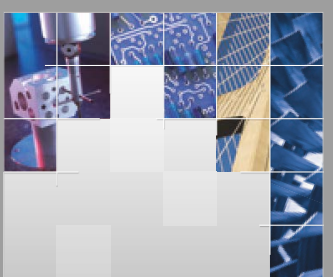

\section{Enfincering}
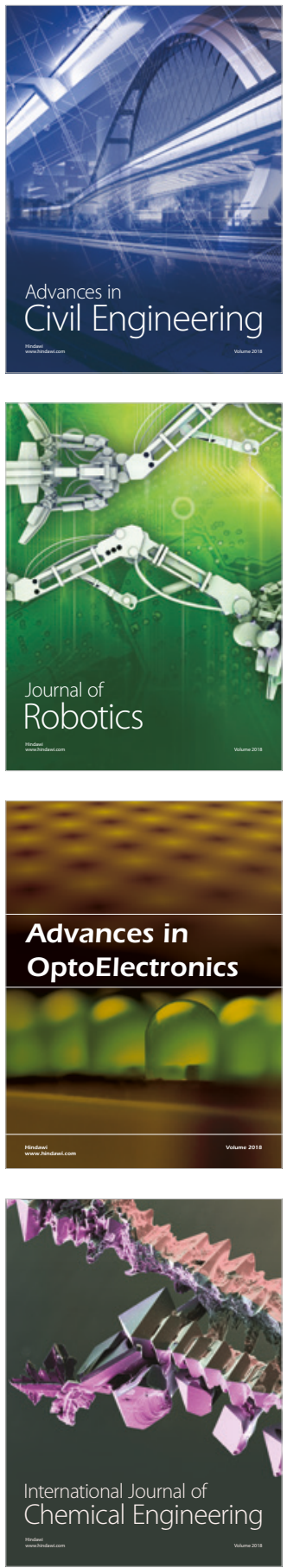

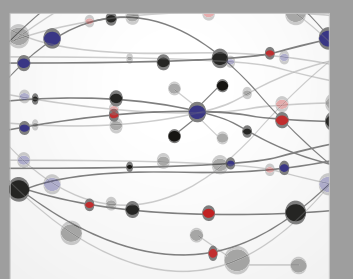

\section{Rotating \\ Machinery}

The Scientific World Journal

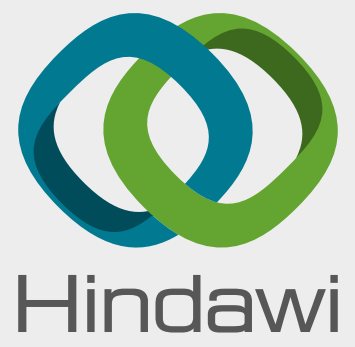

Submit your manuscripts at

www.hindawi.com
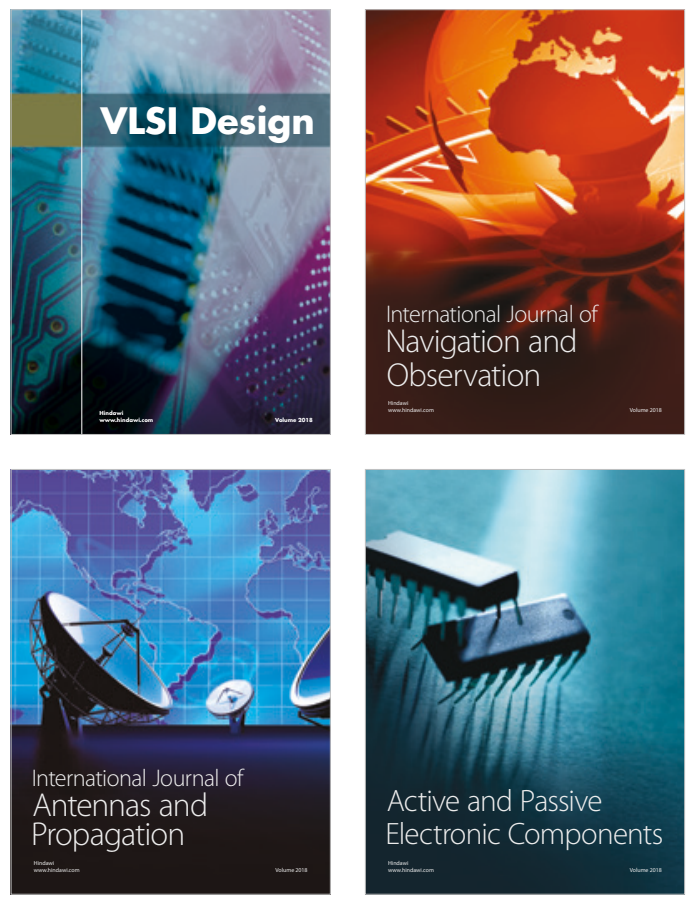
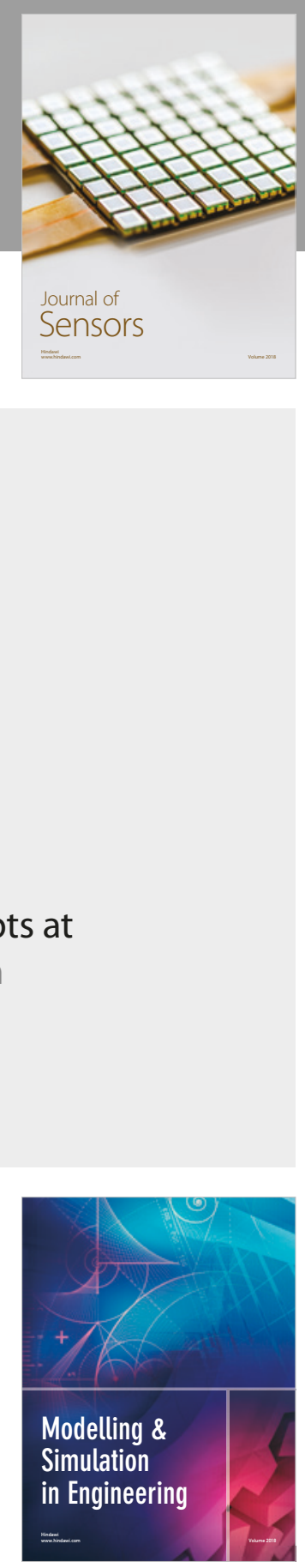

\section{Advances \\ Multimedia}
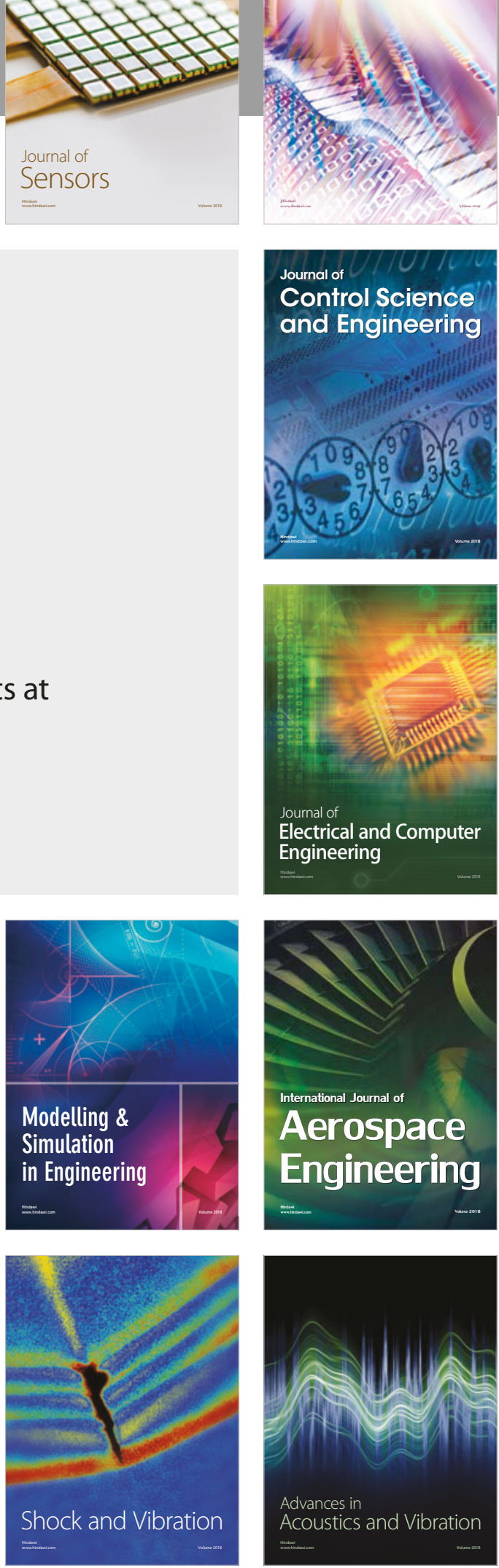